\title{
UM OLHAR SOBRE A FORMAÇÃO ARTÍSTICA: A ESCOLA LIVRE DE TEATRO (ELT) DE SANTO ANDRÉ
}

\author{
Vilma Campos dos Santos Leite ${ }^{270}$ \\ Kátia Paranhos (Orientadora) (UFU)
}

Inúmeras são as escolas de teatro, acadêmicas ou não, e outras vem surgindo no Brasil e no mundo. Nas pesquisas consultadas, até o momento, sobre trajetórias de escolas de teatro no Brasil, pude perceber um tratamento voltado àquelas que já têm minimamente um caminho consolidado ao longo de algumas gerações.

A título de ilustração, trago como exemplo dessas investigações, o de Andrade (1996) que estuda a Escola Dramática Municipal (atual Martins Pena), considerada a primeira escola oficial de teatro do Brasil, fundada no Rio de Janeiro em 1908; o de Castanheiro (2003), que discorre sobre a trajetória do Curso Prático que vai originar o Conservatório Nacional de Teatro em 1953, chegando à nomenclatura de Escola de Teatro da UNIRIO em 1979; de Silva (1989) que discorre sobre a Trajetória da Escola de Arte Dramática de Alfredo Mesquita, fundada em 1948 e que em 1968 vai ser incorporada à Universidade de São Paulo e o de Leão (2006) que estuda o processo da criação da Escola de Teatro da Bahia em 1956, com as encenações e o surgimento de grupos locais, embora já existisse o Conservatório Dramático em Salvador desde 1857.

Esses e outros trabalhos, aliado às análises sobre o processo de formação do ator encontradas em Carvalho (2006) e em Freitas (1998) dão um panorama do como se encontra o trabalho de formação do artista em escolas; enquanto outros autores, não menos importantes, mas que não cabe mencionar aqui, tratam de uma outra modalidade de formação do artista, dentro dos coletivos ou dos grupos de teatro.

É preciso levar em consideração que a disseminação do espaço escolar para a formação específica do ator é recente, remontando ao início do século $\mathrm{XX}$. Dentre alguns pensadores e teatrólogos que surgem a partir desse limiar, e que trazem uma contribuição significativa, para pensar a formatação de centros de estudo ou de formação do ator, citamos Stanislavski, Meyerhold, Brecht, Grotowski e Barba.

Minha opção é pensar a formação do ator na Escola Livre de Teatro (ELT) de Santo André (SP), uma instituição bem recente (fundada em 1990) mantida pela Secretaria de Cultura da Prefeitura do Município de Santo André. Para adentrar no assunto, parto de alguns documentos e da própria experiência de ter realizado minha formação teatral nessa escola, no período de 1990-1992 e de 1997-1998. Acredito que os princípios da instituição estão presentes em mim, provavelmente ressoando em minha própria prática profissional.

Para a conclusão de um trabalho de doutorado sobre a ELT nos próximos anos, pretendo ir além da minha experiência. O objetivo é confrontá-la com a

${ }^{270}$ Doutoranda 
coleta de depoimentos de vários outros sujeitos que fizeram a escola como gestores, mestres e aprendizes ${ }^{271}$. Relacionar ainda com os documentos escritos e iconográficos em arquivos pessoais e da própria instituição, dialogando com a recepção, o relato de funcionários e familiares. Prevê-se ainda, o levantamento das reportagens na imprensa, com a operação não necessariamente nessa ordem. Pretendo chegar a uma trama em que os diversos pontos de vista possam ser considerados para pensar as práticas e as representações na formação teatral daquele contexto, na última década do século $\mathrm{XX}$ e as suas relações com o movimento teatral, especialmente com a cena paulista contemporânea.

Para este texto, ainda em estágio inicial da pesquisa, detenho-me nos anos de 1990-1992 e teço algumas breves considerações a partir de três fontes. Primeiro, uma cópia digitada do Projeto Piloto da Escola (1990). Depois, um texto que discorre sobre a ELT, como terceiro capítulo de " $O$ alfabeto pegou fogo" ensino das artes em Santo André (livro que seria publicado em 1993 e que não o foi devido à mudança do executivo). Os outros capítulos do volume tratam da Escola Municipal de Iniciação Artística (EMIA) e da Casa do Olhar, bens culturais também muito importantes na cidade de Santo André. O teor da parte do texto que trata da ELT foi retomado em 2000, como primeira parte da publicação de Os caminhos da criação, catálogo comemorativo aos dez anos de funcionamento da escola.

Por último, tomo como base alguns parágrafos que falam da ELT no artigo "Não esquecer o rosto e nem a partida. Cultura e ação cultural" assinados por dois sujeitos que trabalharam no processo de institucionalização da escola: Celso Frateschi (Secretário da Educação, Cultura e Esporte) e Altair José Moreira (Diretor de Cultura). O texto se encontra no número 12 da Revista Polis, narrando experiências de gestão democrática em prefeituras petistas dos governos de São Paulo, Belo Horizonte, Santo André, Curitiba e São Bernardo do Campo.

Para além de uma instituição fixa, imóvel, ou etérea, a ELT é entendida neste trabalho como os sujeitos que a formaram ou que foram formados por ela, que a fazem e fizeram. Por esse motivo, a ELT é um "problema" com o qual estou lidando e não propriamente um objeto no sentido inerte da palavra.

Para trazer então esse sujeito-problema chamado ELT, pretendo historicizar e fazer relações com o próprio presente, enxergando o teatro como uma das manifestações artísticas, como um bem simbólico e cultural, sendo necessário ir além das informações, estando atenta para não cair na cilada da efeméride ou de um retomar meramente cronológico.

Para não perder o foco de uma narrativa, já na linha de largada, percebo a necessidade de investir em um entrecruzamento com uma outra área de conhecimento, a História, sobretudo a História e a Cultura, porque esta tem efetuado diálogos profícuos com outros campos do conhecimento como Antropologia, Sociologia, Filosofia, Geografia, Psicologia, Arte, entre outras. Dessa última, na seara do Teatro, os trabalhos historiográficos até o presente

\footnotetext{
${ }^{271}$ A nomenclatura mestre e aprendiz refere se ao professor e ao aluno da ELT. Outro termo bastante utilizado para esses papéis dentro da instituição é o de artista-orientador e ator-aluno.
} 
momento, estão sendo realizados principalmente pelos estudos da obra de dramaturgos e de grupos teatrais, existindo uma predisposição para acolher um estudo que trata da institucionalização de uma escola de Teatro.

A História tem nos ajudado a perceber a que a prática artística da ELT não está alheia aos acontecimentos à sua volta, relaciona-se histórica e socialmente, embora não possa ser entendida apenas como reflexo ou espelho, o que reduziria o próprio potencial dos sujeitos. Inserida em um processo tensiona e harmoniza, influencia e sofre influências.

A seguir uma longa, mas necessária citação, onde se percebe a vontade política e o empenho na realização deste projeto na voz do diretor e secretário de cultura:

Era um momento propício para pensar uma escola que tivesse a preocupação com a criação e desse ao cidadão um instrumento para fazer teatro. No entanto sua base deveria conjugar a formação e a prática. Com todo o cuidado, foi elaborada uma metodologia que concebesse a arte de representação como lugar de formação do indivíduo, em que a dimensão humana precedesse a dimensão profissional, uma escola provocativa de atitudes independentes. A proposta básica da Escola Livre de Teatro de Santo André (ELT), coordenada por Maria Thaís Lima dos Santos, objetivava a mobilidade de uma oficina cultural sem perder de vista a perspectiva funcional do aluno, cuidar do seu crescimento artístico e instrumentalizá-lo em termos de conhecimento teatral, sem amarrá-lo a obrigações curriculares pré-fixadas pelo ministério da Educação. Ser, enfim, um lugar de experimentação. A escola trabalhou com artistas-pesquisadores de reconhecida capacidade de trabalho interessados em compartilhar com os alunos. $O$ espaço da ELT abrigou ferramenteiros, comerciários, cobradores de ônibus, jornalistas, sociólogos, artistas plásticos: todos tinham como convergência a vontade de fazer teatro. Na segunda etapa, a coordenação da escola com seus artistas-educadores definiram que era imprescindível a relação individual entre orientadores e alunos. A escola, após a sua trajetória de um ano, redefiniu a relação quem ensina/quem aprende estabelecendo que ambos são pesquisadores com uma característica comum: a procura de uma nova ética da criação, onde ser artista não significa perder a 'antena do mundo'. (FARIA \& SOUZA, 1993, p. 68-69.)

As palavras dessa citação dialogam diretamente com o Projeto-Piloto que deu início à escola de autoria de Maria Thaís Lima Santos e com o capítulo de Alfabeto Pegou fogo na concepção da mesma autora em conjunto com Sérgio Ricardo de Carvalho.

Chamo a atenção de três aspectos. Primeiro, a pretendida autonomia provocativa de atitudes independentes. Para se chegar a essa autonomia, a formação da escola não se limita a uma formação prática do fazer, mas menciona uma formação humana, tocada pela individualidade e pela cidadania. Celso e Altair no mesmo artigo mencionam o projeto cultural hegemônico 
presente no país como herança dos Governos Militares e de que estão na contracorrente do projeto autoritário naquele momento do Governo Federal. Citam a necessidade de criar "ilhas de desordem", termo cunhado por Heiner Müller e que significa o cultivo do "humano no que ele tem de livre e criativo e que se dê a possibilidade de distinguir o oceano das ilhas, dos continentes, do céu e das palavras" (Faria \& Souza, 1993, p.64)

A defesa por uma autonomia também aparece na introdução do Projeto Piloto, ao lado da defesa da importância de um centro facilitador para que as pessoas interessadas possam estudar mais profundamente o ofício teatral. Destaca-se no projeto, um posicionamento do Estado enquanto facilitador e não apenas provedor de uma produção autônoma de bens culturais.

Um segundo aspecto a se destacar do texto é o comprometimento social quando afirma que o artista não pode perder a antena do mundo. Essa frase dialoga com o início do Projeto Piloto, em que Maria Taís traz uma significativa epígrafe de Eugênio Barba “(...) sejam quais forem as motivações pessoais que te trouxeram ao teatro, agora que exerces a profissão, deves encontrar um sentido que vá além da tua pessoa, que te situe socialmente frente os demais. No corpo do projeto essa idéia é reiteranda na expressão caberá a cada experiência artística encontrar o elo social (...).

Por último, destaco a diversidade de sujeitos presentes na escola, mencionada pelas profissões e pela formação escolar, que não poderiam estar frente a frente, caso a opção da Escola fosse por seguir as regras do Ministério da Educação e Cultura. O projeto explicita o porquê não pretende dar o "número" do Registro da Profissão do Ator, rebelando-se com a estrutura acadêmica, em contraposição a uma formação que se pretende na prática do ofício.

"Sob o signo da liberdade" como aparece no Alfabeto pegou fogo livre não significa ausência de rigor, mas serve para ligar dois outros conceitos tão complexos e de difícil conjunção "escola" (a práxis do ensino) e teatro (uma práxis da arte). O ponto de partida para um repertório comum de trabalho entre mestre e aprendizes se faz com um acordo entre as partes. A diferença das turmas no contato prévio com o teatro, com a profissão ou formação escolar puderam ser respeitadas. De 1990-1992 houve uma base comum de trabalho de formação de ator pautados na ação física e no jogo.

Como a obra do artista está no próprio corpo, é a partir da sua presença real que se faz o trabalho de percepção, treino vocal, corporal e de interpretação. A partir daí e da sua interação com o outro se estabelece a noção de jogo. Ainda em Alfabeto pegou fogo podemos conferir que no desenvolvimento deste potencial, o que demanda tempo, vontade e dedicação constante, surge a necessidade de experimentá-lo no exercício artístico por excelência: a criação(p.63). As encenações surgem de uma trajetória estabelecida na relação entre os artistas-orientadores e atores-alunos e não como uma proposição da Escola.

É óbvio que muitos outros aspectos poderiam ser trazidos à cena dessa citação. Muitas outras passagens das fontes poderiam ser acionadas, mas o objetivo aqui não é esgotamento da reflexão e sim, o de lançar um primeiro 
olhar sobre a pedagogia da escola, a partir do seu próprio discurso, considerando que aquele momento e espaços específicos influenciam e são influenciados pela experiência da escola.

Os textos consultados não são textos inocentes e têm uma recepção determinada. O artigo da revista e de o capítulo de livro é passível de serem lidos como uma prestação de contas. Já o projeto pode se destacar como uma proposta de convencimento ou uma carta de intenção.

Esses desejáveis objetivos de autonomia, comprometimento social e rebeldia, entre outros aspectos que podem ser relevados no texto se manifestaram na prática? São reconhecidos pelos seus sujeitos, sejam os mestres, os aprendizes ou seus espectadores (os familiares, os membros da classe teatral, os funcionários)?

Deverei enfrentar e ampliar essas questões nas entrevistas com os sujeitos, para além dos pontos elencados na leitura desses e outros documentos, enxergando em cada enunciado os possíveis confrontos com outros pontos de vista e buscando nos discursos as intenções e as pretensões.

\section{Referências}

ASLAN, Odette. $O$ ator no século XX. São Paulo: Nova Cultural, 1999.315 p. ANDRADE, E. M. F. Escola Dramática Municipal - a primeira escola de teatro do Brasil. 1908-1922 - subsídios para uma história da formação do ator brasileiro. 1996, 160p. Mestrado em Teatro. Rio de Janeiro: Unirio, 1996.

CAMACHO , T. Cultura de trabalhadores e crise política. Santo André: Fundação de Cultura. Santo André, 1999. 191 p.

CARVALHO, E. História e formação do ator. São Paulo: Editora Ática, 1989.231p.

CASTANHEIRO, J. Do curso Prático ao Conservatório de Teatro: origens da Escola de Teatro da Unirio, 162 p. Dissertação (Mestrado em Teatro) Rio de Janeiro: UNIRIO, 2003. $162 \mathrm{p}$.

CORREA, R. C. C. Cenário, Cor e luz: Amantes da Ribalta em Santa Maria (19431983). Rio Grande do Sul: Editora UFSM, 2005. 152 p.

DUVIGNAUD, J. Sociologia do Comediante. Rio de Janeiro: Zahar Editores, 1972. 261p.

FARIA, H \& SOUZA, V. (orgs.) Experiências de Gestão Cultural Democrática. São Paulo, PÓLIS, 1993, 120 p.

FREITAS,P.L. Tornar-se ator. Uma análise do ensino de Interpretação no país. Campinas: Editora da Unicamp, 1998, 257p.

LEÃO, R. M. Abertura para outra cena: uma história do teatro na Bahia a partir da criação da Escola de Teatro. Bahia: Universidade Federal da Bahia. 2006, 278 p.

SANTANA, A. P. Teatro e formação de professores. São Luís: EDUFMA, 2000. 234p. SANTO ANDRÉ (SP) Secretaria de Cultura, Esporte e Lazer. O alfabeto pegou fogo. Ensino das Artes em Santo André. 1992 (mimeo).

SANTO AMDRÉ (SP) Secretaria da Cultura, Esporte e Lazer. Os caminhos da criação. Escola Livre de Teatro, 10 anos. Prefeitura Municipal de Santo André, Secretaria da Cultura, Esporte e Lazer - Santo André: Departamento de Cultura, 2000.

SILVA, A. S. Uma oficina de Atores. A Escola de Arte Dramática de Alfredo Mesquita. São Paulo: Ed. Edusp, 1989. 284p.

SILVA, J. A. P. A cena brasileira em Santo André: 30 anos do Teatro Municipal. Santo André. Secretaria de Cultura, Esporte e Lazer, 2001. 311 p. 